\title{
Does disinfecting water lines work?
}

\author{
Evaluation of the efficacy of Alpron disinfectant for dental unit water lines
}

\section{A. J. Smith, S. McHugh, I. Aitken and J. Hood Br Dent J 2002; 193: 593-596}

\section{Aims}

To assess the efficacy of a disinfectant, Alpron for controlling microbial contamination within dental unit water lines.

\section{Methods}

The microbiological quality of water emerging from the triple syringe, high speed handpiece, cup filler and surgery hand wash basin from six dental units was assessed for microbiological total viable counts at $22^{\circ} \mathrm{C}$ and $37^{\circ} \mathrm{C}$ before and after treatment with Alpron solutions.

\section{Results}

The study found that the use of Alpron disinfectant solutions could reduce microbial counts in dental unit water lines to similar levels for drinking water. This effect was maintained in all units for up to 6 weeks following one course of treatment. In four out of six units the low microbial counts were maintained for 13 weeks.

\section{Conclusions}

Disinfectants may have a short term role to play in controlling microbial contamination of dental unit water lines to drinking water quality. However, in the longer term attention must be paid to redesigning dental units to discourage the build up of microbial biofilms.

\section{IN BRIEF}

- This paper suggests that the use of Alpron disinfectant may play a short term role in controlling microbial contamination of DUWLS.

- The methods described could be readily used in general dental practice.

- Dental staff and patients should benefit from the reduction in microbial loads in DUWLs.

\section{COMMENT}

The presence of large numbers of bacteria in water exhausted from dental units has been reported for several decades. However, to date there is very little direct evidence that it is a health hazard to either patients or surgery staff. Nonetheless, there is circumstantial evidence that would suggest that dental staff in particular might be occupationally exposed to Legionella sp. It would therefore seem sensible, that having identified a risk, attempts should be made to reduce that risk to as low a level as is possible.

This paper evaluates, over a period of 13 weeks, a product that is currently in the market place that appears to be very effective and safe. As a result of the use of this product, the water from the units tested in the study was altered from being heavily contaminated to potable as defined by the EU directive on the quality of water intended for human consumption. The product is simple to use once the initial biofilm has been removed and entails very little extra work for surgery staff during the working day. Removal of the biofilm from the water lines in the dental unit has the added bonus of increasing the flow through the unit although this was not part of this study.

The authors are at pains to point out that chemical treatment of the dental unit water supply is very much a short-term solution. The long-term answer must be for a radical redesign of the dental unit to engineer out the problem. Manufacturers of dental units must have known about the problem for some time yet little or no progress seems to have been made in this direction.

The publication of this paper will be of interest to the staff of the BDA because there are an increasing number of practitioner enquiries regarding treatment of dental unit water. There is now published evidence that there is a readily available product for which there is evidence of effectiveness.

Martin Fulford. General Dental Practitioner, Shepton Mallet. 